Action Lock. As usual, the male and female division locks were controlled by different keys, and both by the master key. Objections have been urged against the usual form, that the bolt is twice thrown out, necessitating a large lock and a weakening of the lock rail; the master key throws an obstruction in the way of the journeyman key, thereby causing breakage and damage to lock and key; the master key is formed by extra cutting, thereby rendering it easy to convert a journeyman key into a master key with a slight application of a ward file. The advantages claimed for the Excommunicator Action Lock are:-1. The bolt is only thrown out once. 2. A second turn of the master key throws the lock out of gear, so that the ordinary key turns in the lock without touching the bolt or straining the parts. 3. All the working parts are made to standard gauge and fixed with screws, so that repairs are easy and occupy a minimum time. 4. The master key is least cut, thereby making it impossible to convert a journeyman key into a master key without special skill. 5. The whole parts are simple in construction and simple in action. 6. The cost of altering old locks to this design is very small.

Members afterwards dined together at the Grosvenor Hotel, Chester.

\title{
SPRING MEETING OF THE SCOTTISH DIVISION.
}

A meeting of the Scottish Division was held in the hall of the Faculty of Physicians and Surgeons, Glasgow, on Thursday, 9th March, 1899. In the unavoidable absence of Dr. Urquhart, President of the Association, Dr. Clouston was called to the chair. The other members present were Drs. Campbell Clark, Carswell, Graham, Hotchkiss, Ireland, Carlyle Johnstone, Macpherson, Watson, and Turnbull (Secretary).

The minutes of the previous meeting were read and approved.

Hugh de Maine Alexander, M.D., Assistant Physician, Perth District Asylum, and Joseph Green, M.B., Ch.B., Assistant Physician, Gartloch Asylum, were admitted as members of the Association.

It was agreed to nominate Dr. Turnbull for the Divisional Secretaryship; and after discussion it was remitted to the Chairman and the Secretary to prepare suggestions to the Council for the filling up of the vacancies which will occur in July next by the retiral of one Scottish representative on the Council and of one of the Examiners for Scotland.

Dr. Campbell Clark asked what had been the outcome of the recommendation made by the Division in regard to the payment of the expenses of the Secretaries; and it was explained that the matter was not yet decided, but would be under consideration by the Council at the May meeting.

Dr. Carlyle Johnstone referred to the question of having reporters at the Divisional meetings, and mentioned that a motion for dispensing with reporters is to be submitted to the Council at the meeting in May.

Dr. IRELAND read a paper on "The Causes of the Increased Frequency of Suicide," which will appear in a future number of the JouRnAL.

\section{INEBRIATES' ACT.}

The Chairman said he would like to make a few remarks on the "Inebriates" Act." Lord Balfour appointed a Committee to consider and report as to the working of the Act in Scotland, at first without a doctor on it, but afterwards did him the honour of adding him to the Committee. The Committee did their very best to draw up regulations to work this Act. In regard to himself, he always had this in mind in helping to draw these regulations, that they should be suitable not only to the present Act, for the criminal inebriates for which that Act was passed, but to the future Act which they all hoped to get soon for the non-criminal inebriates, so that the rules and regulations will practically suit the one as well as the other. He might mention the provisions that have to be made. First, a state inebriate reformatory ; very likely a portion of the General Prison, Perth, will be taken for that purpose. Second, certified inebriates' reformatories, which can be set up by any Town Council or County Council or private individual; and those will, he hoped, 
be put up in Scotland in various local centres within a short time. They all ought to do their utmost to get the magistrates to take an interest in this question, and to set up one of these reformatories. Third, to license out inebriates in the same way as they license out lunatics, to be under the control of respectable trustworthy people, and thus bring them under the influence of family life. The members of Committee were disappointed with an alteration made in the regulations as first proposed, with the result that now a man must be three months in an inebriate institution before he can be licensed out, which he thought a mistake. It would have been better to have power to license certain suitable cases out at once. The Committee also recommended that $8 s$. a week should be allowed by the Treasury, but this had been cut down to $6 d$. a day, $3 s$. $6 d$. a week, which was an utterly inadequate sum for the boarding out of any person, and will simply nullify the boarding-out clauses.

\section{INCIPIENT AND UNCONFIRMED INSANITY.}

\section{Deputation to the Lord Chancellor.}

The following is a report of the interview which a deputation of the British Medical and Medico-Psychological Associations had recently with the Lord Chancellor.

The deputation consisted of Dr. W. Douglas, Mr. George Eastes, Dr. W. J. Mickle, Dr. G. E. Shuttleworth, Dr. Fletcher Beach, Dr. G. F. Blandford, Dr. H. Rayner, Dr. G. H. Savage, Dr. Ernest W. White, Dr. Dawson Williams, and Mr.

Francis Fowke, General Secretary of the British Medical Association.

Dr. Farquharson, M.P., having briefly introduced the deputation,

Dr. RAYNER said that the proposal which the deputation wished to make had been the subject of a resolution passed in 1896 by the British Medical Association. $\mathrm{He}$ (Dr. Rayner) had been moved to read the paper which led to the resolution by his experience in the early treatment of insanity, especially at the out-patient department of St. Thomas's Hospital. In every case of mental disease there was a stage between health and certifiable insanity. That was shown by many recoveries without certification, and by the statements as to the duration of the disorder prior to admission into asylums. The cases were nearly always reported to have been mentally affected for three, six, or twelve months. In order that the existence of such a stage should be legally recognised, the deputation proposed that the Lunacy Acts should be amended by a clause similar to that which had been in force for thirty years or more in Scotland.

The LoRd Chancellor asked to be referred to the provision in the Scots Act.

Dr. RAYNER, having pointed out the section of the Scots Act: "Provided that this enactment shall not apply to any case where the party so received and kept has been sent to any such house for the purpose of temporary residence only, not exceeding six months, and under the certificate of a medical person, which certificate shall be in the form of Schedule (G) hereunto annexed." The advantages of the proposed clause were that the Commissioners of Lunacy would be informed of the number of cases treated, of the duration of treatment, and the persons undertaking the treatment. This would give the Commissioners powers of supervision when necessary, and probably ultimately of regulating the treatment by such provisions as their experience would suggest. No pretext or excuse would be left to persons who now evade the law. The deputation believed those improvements would lead to a large amount of recovery in the early stage, which did not now take place.

Dr. BLANDFORD said that the medical profession had been teaching for many years that insanity was a disorder to be treated by medical means, and that it was curable in the early stages. It was therefore of the greatest possible importance that it should be treated at a very early stage. The Lunacy Act of 1890 had put a different complexion upon the matter. It enacted that every person who was of unsound mind should be incarcerated by the order of a magistrate.

The LORD ChANCELlor pointed out that Dr. Blandford was somewhat misstating the effect of that Act, for which he was responsible. It was not that a person of 